\title{
ENDODONTIC TREATMENT OF A MAXILLARY CENTRAL INCISOR WITH ARRESTED ROOT DEVELOPMENT: A CASE REPORT
}

W.A. Annuar, R.A. Rahman, J. Bahadun. Endodontic

Treatment of $A$ Maxillary Central Incisor with Arrested Root Development: A Case Report. Annal Dent Univ Malaya 2008; 15(2): 82-88.

\begin{abstract}
Arrested root development of permanent teeth can occur due to local factors such as infection and trauma or general factors such as radiation and odontodysplasia. This case report presents a 11 tooth with arrested root development requiring endodontic treatment. Following obturation with MTA, a minor surgical procedure was performed to remove periapical pathologic tissue. The tooth had remained asymptomatic at the 6-month review and the case will be followed-up for at least 2 years to ensure complete healing.
\end{abstract}

Key words: arrested root development; MTA

\section{INTRODUCTION}

Variations in the shape of root or canal configurations resulting from anomalies in root formation or arrested root development, may have an impact on endodontic treatment. Several cases of root anomalies of central incisors have been reported in the literature (1-4). Although several studies indicated that maxillary central incisors would present with one root and one canal in $100 \%$ of cases $(5,6)$, others have reported cases in which the central maxillary incisors presented with two canals and even with two roots (7-9).

Arrested root development in a permanent tooth may be as a result of local factors such as infection, trauma, teeth in the fracture line or localized odontodysplasia. General factors namely, radiation to the maxilla or mandible during the period of root development as well as regional odontodysplasia would also halt root development (10). Partial or complete arrest of root formation is a complication occurring in $2 \%$ of traumatized deciduous teeth (11). It is typically associated with the avulsion of a primary maxillary incisor between 5 and 7 years of age.

This report describes endodontic treatment performed on an abnormal root of a maxillary central incisor as a result of arrested root development due to childhood trauma.
Case Report

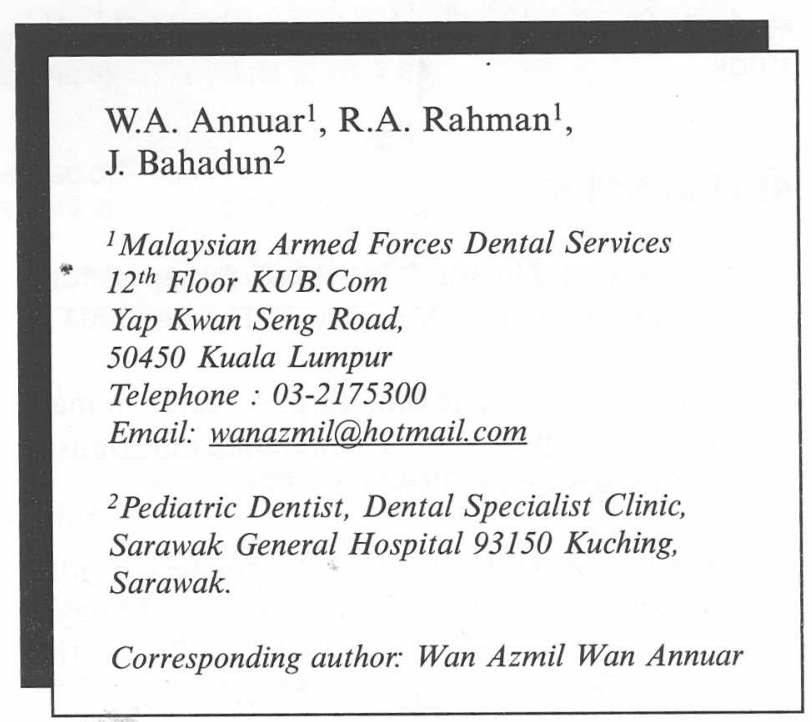

\section{CASE REPORT}

A 28 year-old navy personel was referred for endodontic treatment of maxillary right central incisor with periapical abcess and draining sinus at the labial mucosa. His medical history was unremarkable. Past dental history revealed an episode of trauma to the maxillary anterior region during his childhood. Patient was unable to recall his age during which the trauma occurred. The tooth had several episodes of on and off pain with labial swelling for the past one year.

Clinical examination revealed a sinus tract between right central and lateral incisor with pus discharge (Figure 1). The sinus tract was tracked using gutta percha point and radiograph was taken (Figures 2 \& 3). Clinical crown morphology was normal with temporary restoration on the palatal surface. It was also discoloured and slightly tilted mesially. The tooth was firm and probing depth at the gingival sulcus was normal. However it was tender to percussion and the tissue around the complaint area was also tender to palpation. Otherwise, his dentition was intact and the soft tissue healthy.

Intraoral periapical radiograph taken, revealed unusual root anatomy of the right central incisor. The root was short, with a large canal and broad apex (Figure 4). Periapical radiolucencies were noted at its apex. Patient did not respond to electrical and thermal tests. From the clinical as well as radiograph examination a diagnosis of chronic periapical abcess was made. 


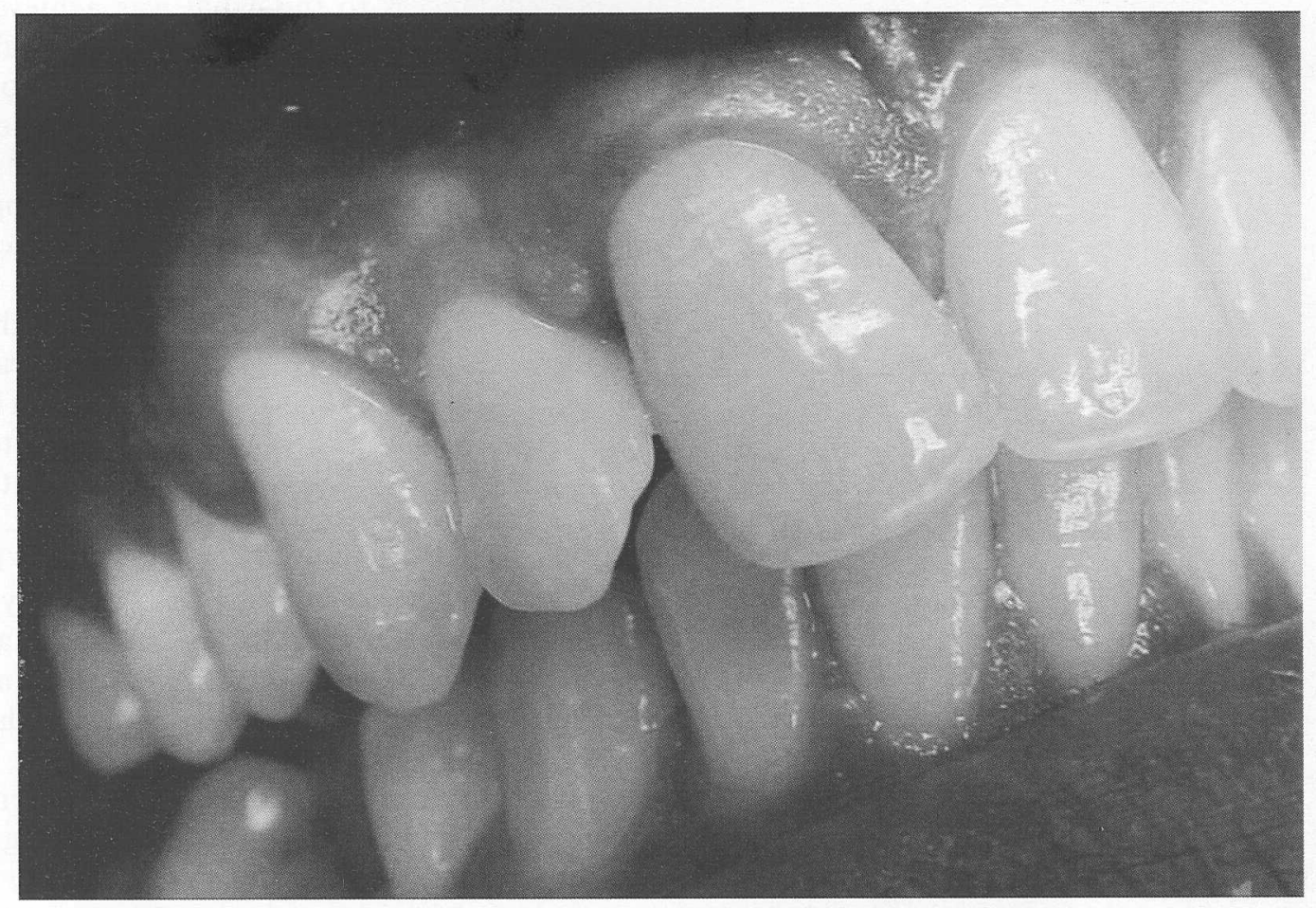

Figure 1: Sinus with pus discharge between right central and lateral incisors.

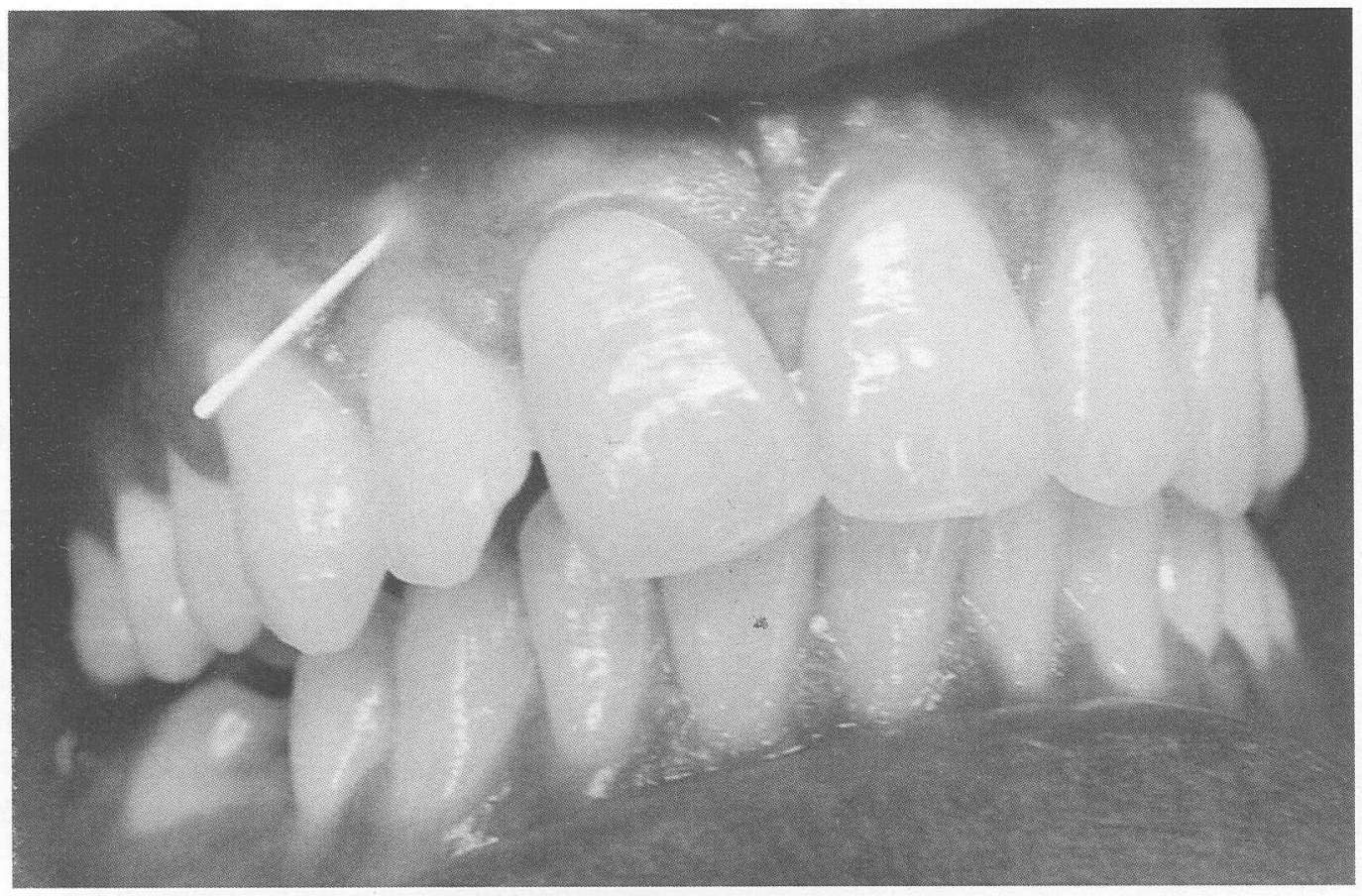

Figure 2: Labial sinus tract was tracked using gutta percha. 


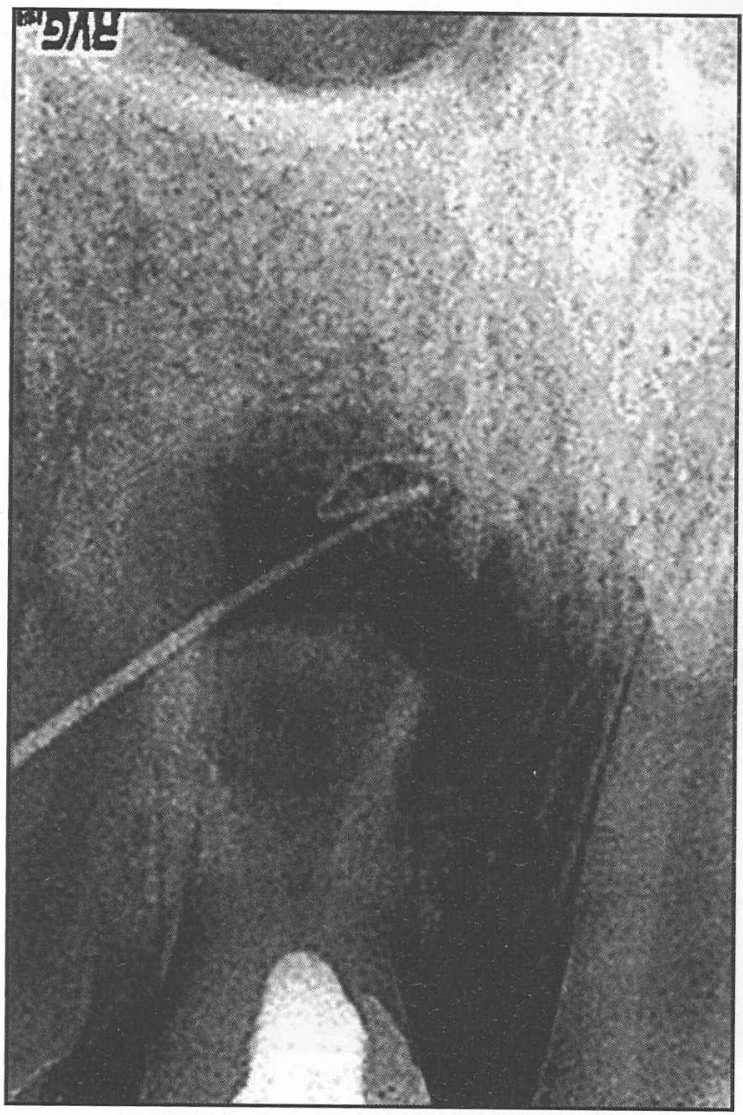

Figure 3: Radiograph showing tracking of sinus tract using gutta percha.

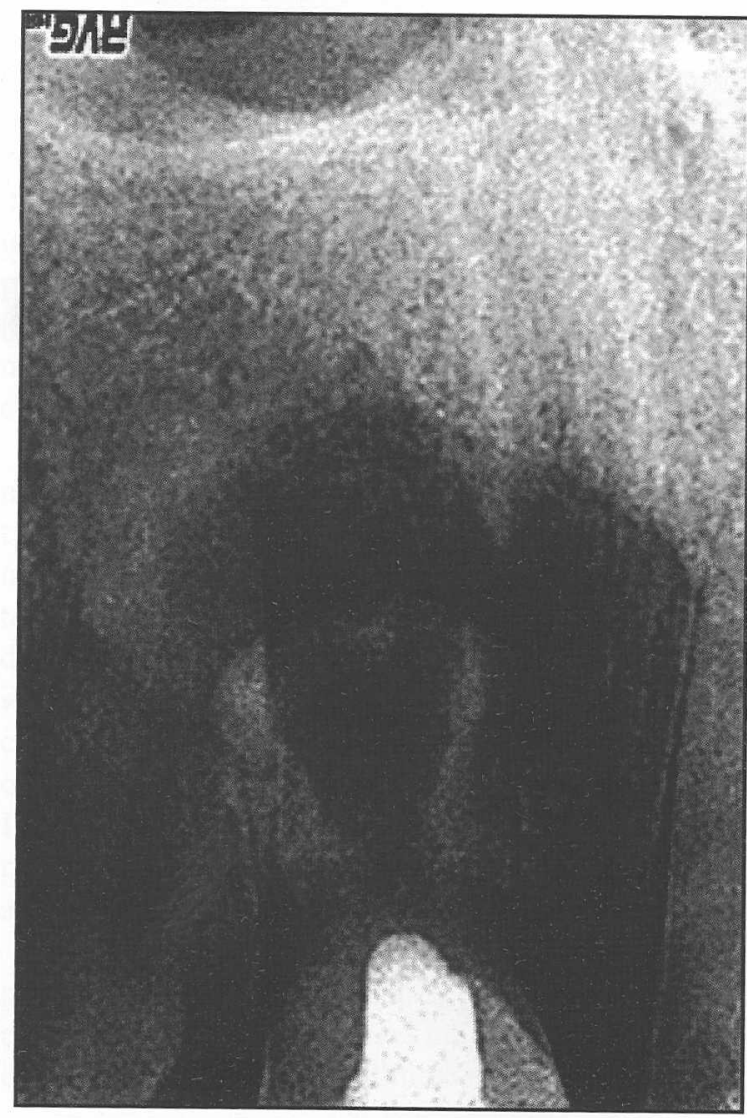

Figure 4: Pre-operative periapical radiograph view of right central incisor showing abnormal root form.
The tooth was anesthetized and isolated with rubber dam and the temporary restoration was removed. Access to the canal was achieved. The canal was cleaned by filing around its wall using headstrome size \#50 with copious irrigation using $5.25 \%$ Sodium Hypochloride $(\mathrm{NaOCl})$ solution. Intracanal medicament (Endopaste, ADM, Australian Dental Manufacturing) was applied in the canal and cavity access was covered with temporary restoration.

The intracanal medicament was left in the canal for one week. After a week the patient was called for review. There was no signs and symptoms. The sinus had healed and the canal was again irrigated with $5.52 \%(\mathrm{NaOCl})$ solution to remove the intracanal medication and then dried with paper point.

The canal was obturated with Mineral Trioxide Aggregate (MTA) (ProRoot MTA, Dentsply Tulsa). MTA was mixed according to the manufacturers instructions and gently packed into the canal with the back of a paper point size \#80. After the MTA insertion, a radiograph was taken to ensure adequacy of obturation. A semi permanent restoration was placed at the access opening. At the same visit minor surgery was performed to remove the pathologic tissue at the apical area. Mucoperiosteal flap was raised from distal of right lateral incisor to mesial of left central incisor (Figure 5). During the surgery the pathologic tissue at the apex of the root was removed (Figure 6) and sent to the pathology department for histopathology examination (HPE). The excess MTA at the apex was removed and the apex was burnished (Figure 7). The flap was then repositioned and sutured with 40 Vicryl.

The patient returned one week later for review and suture removal (Figure 8). The surgical site had healed and the tooth was asymptomatic.

\section{DISCUSSION}

In the above case, the abnormal root formation was a result of arrested root development.

Cleaning and shaping of the canal system could not be done as in ordinary canals. There was no need to perform canal shaping as the canal was already large. Light filing to clean the canal wall was performed in view of the thin dentin. Excessive filing would weaken the wall and lead to root fracture. The canal was irrigated with full strength $5.25 \% \mathrm{NaOCl}$ because of its known antimicrobial activity, ability to dissolve necrotic tissue and to aid in the debridement of the canal system.

Conventional canal sealing method such as lateral condensation was not possible due to the abnormal canal shape. There were two possible methods, either using the themoplastic gutta percha system such as Obtura or using the biocompatible 


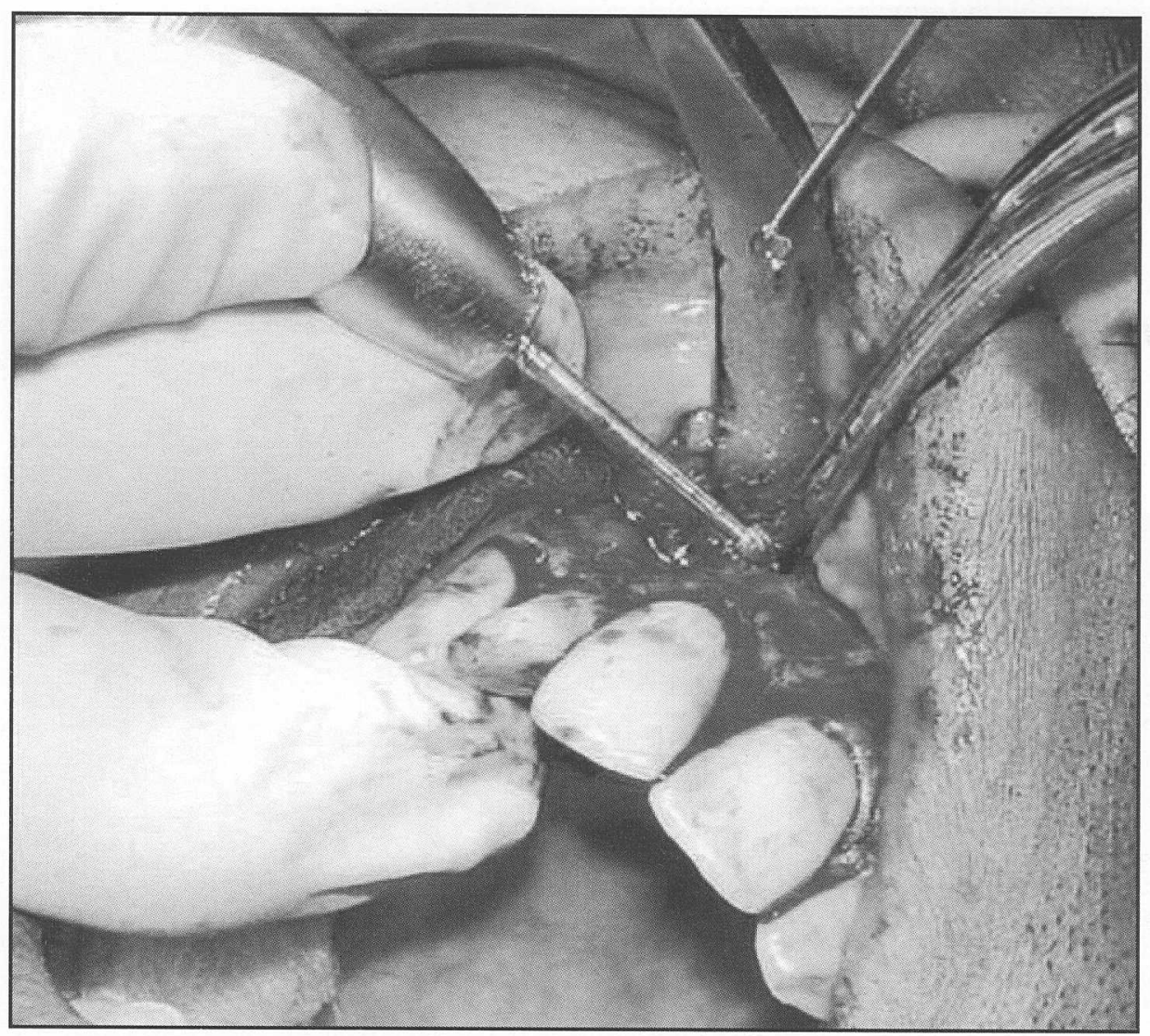

Figure 5: Mucoperiosteum flap raised and pathologic tissue was being removed.

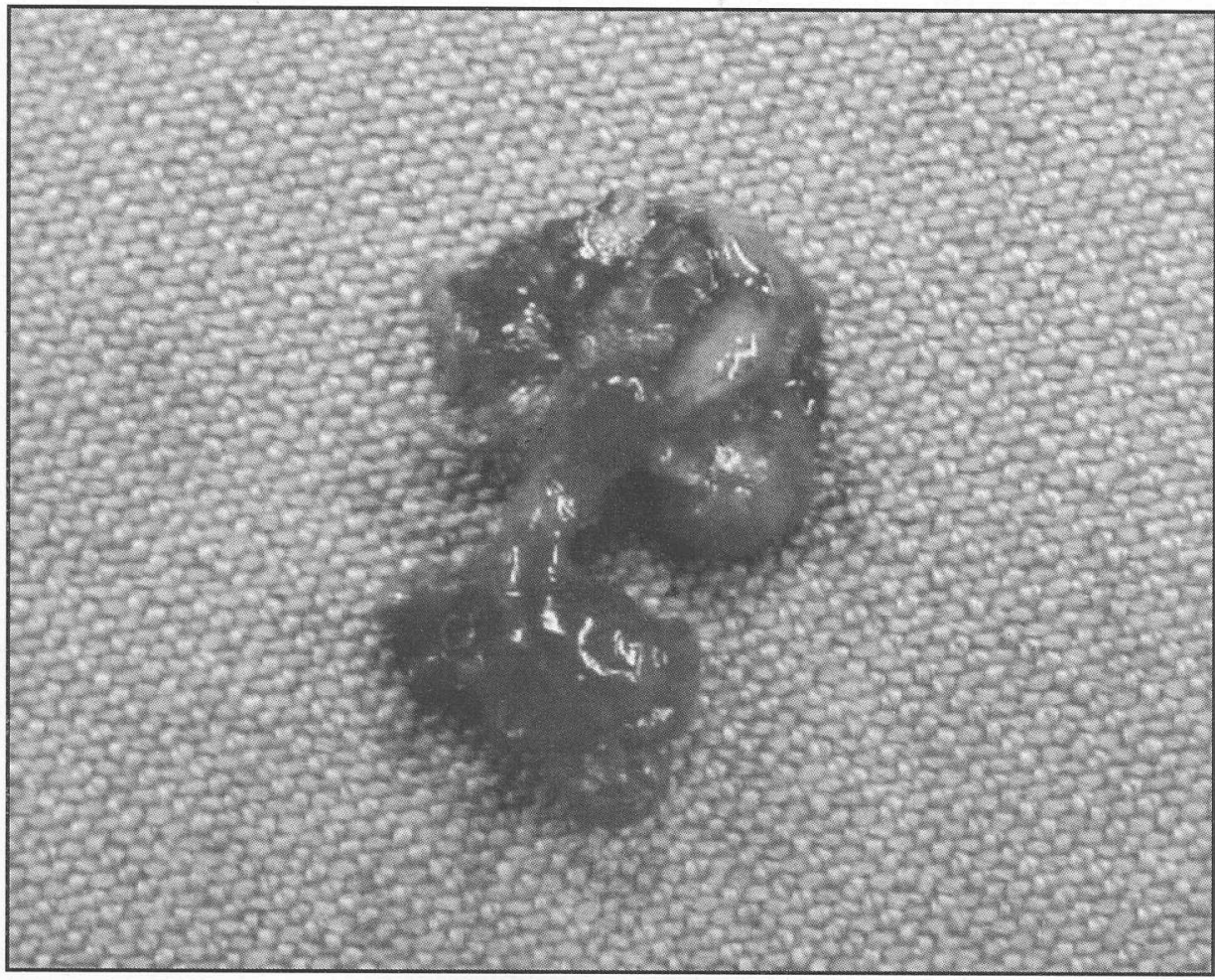

Figure 6: Pathologic tissue removed from the affected area. 


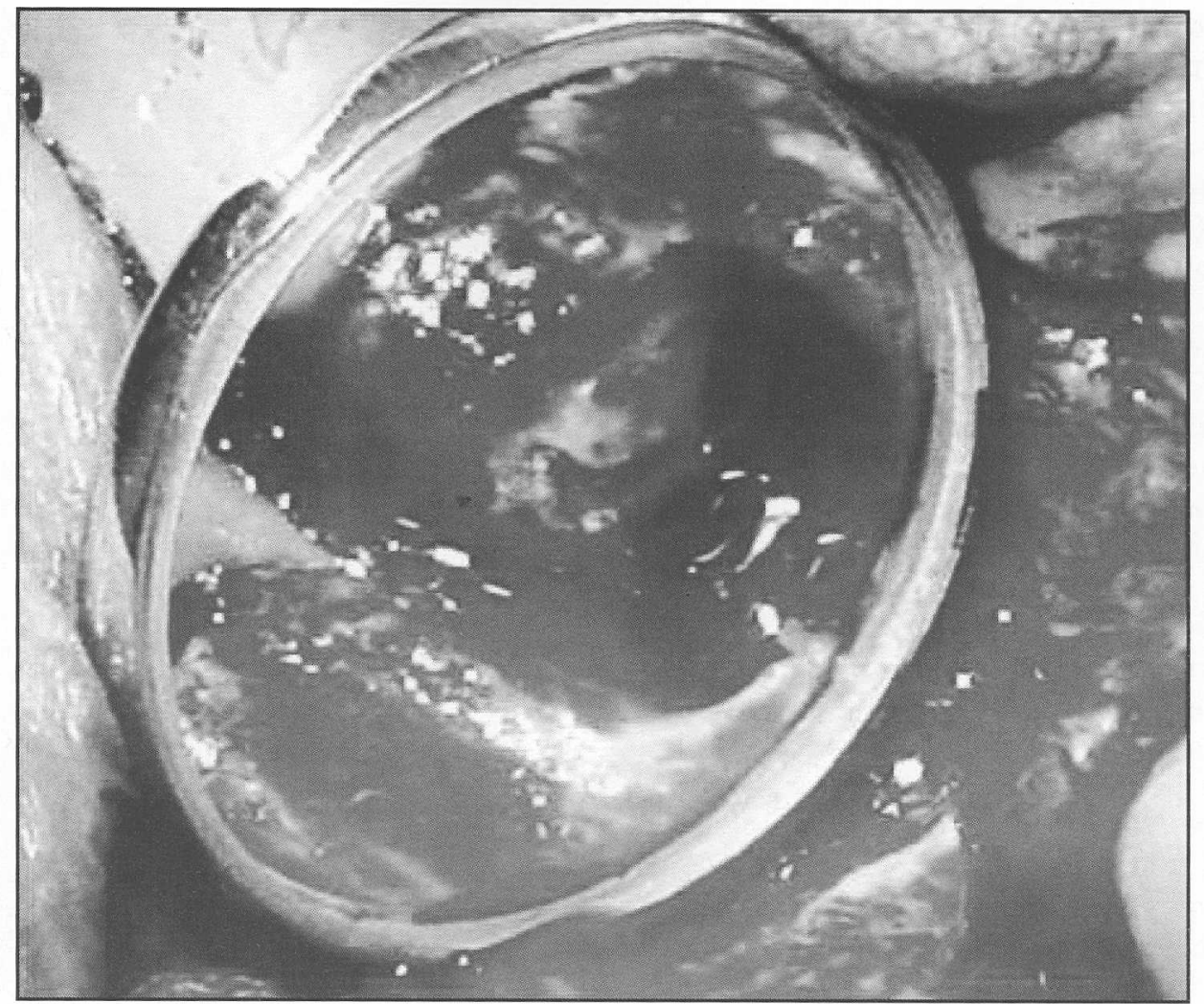

Figure 7: Root apex after removal of the pathologic tissue and excess MTA.

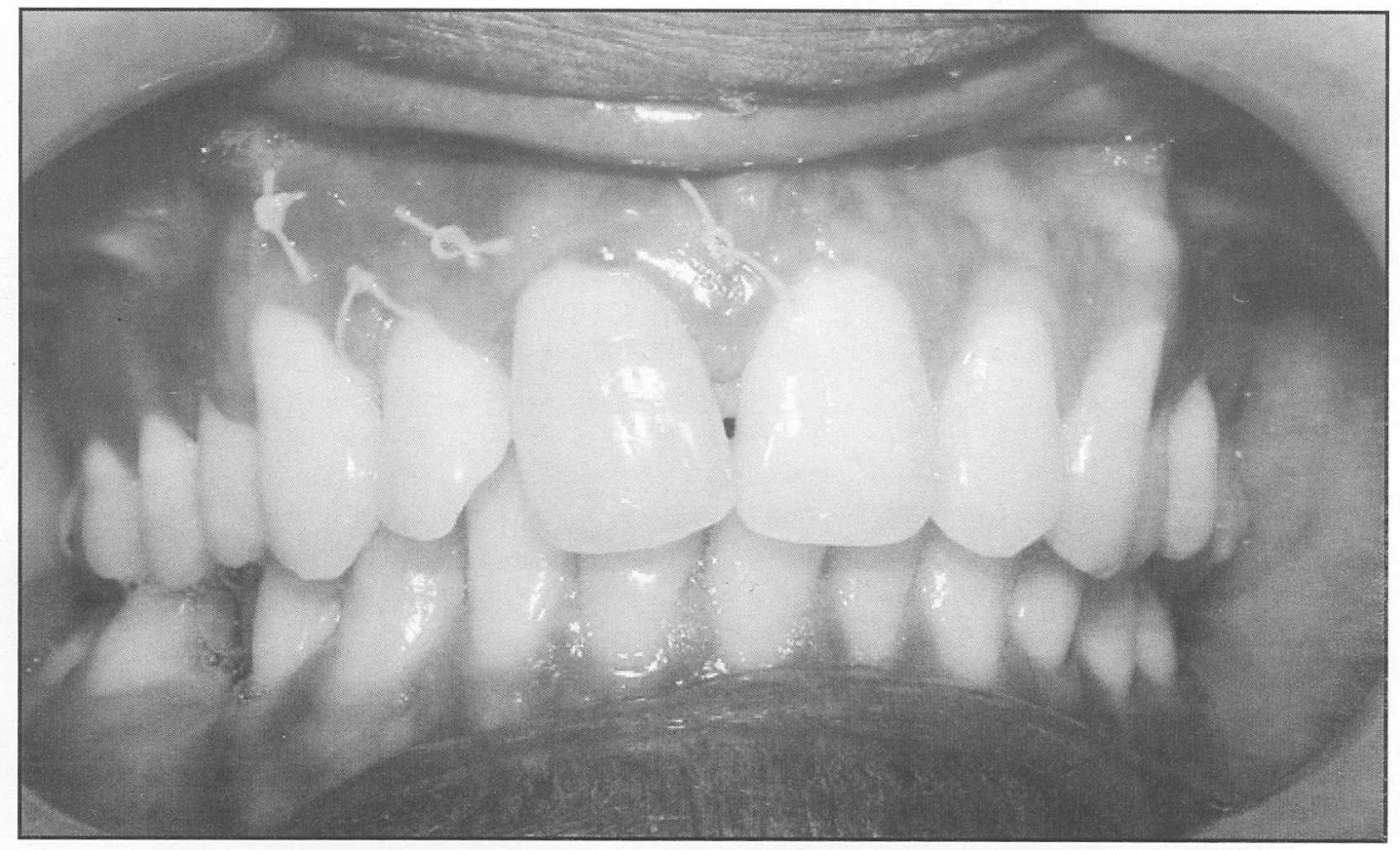

Figure 8: One week after the surgery.

filling material such as MTA. In this case MTA was used. MTA appears to be equal or superior to other root end filling material, with respect to biocompatibility, bacterial leakage, marginal adaptation, solubility and compressive strength $(12,13)$. This material also appears to induce cementogenesis with new cementum deposition on the surface of the retrofilling material $(13,14)$. In 
case with inadequate haemorrhage control, MTA has been reported to be superior to other root filling materials such as IRM or Super EBA.

However, the downside of this material are that it is expensive and its difficult intraoperative handling and prolong setting time of approximately 3 hours. Ideally, therefore, the surgery should have been carried out the following day.

The objective of periapical surgery is to obtain hard tissue regeneration. This is often achieved by the removal of periapical pathologic tissue and exclusion of any irritants within the physical confines of the affected root (15). This procedure has been reported to have high success rates (16).

The tooth remained asymptomatic at 1-month and 6-month review (Figure 9). Radiographic appearance showed some regeneration of bone at the apical area (Figure 10). This patient is currently under regular 6-monthly follow-up. It is hoped that by 2 years, the post-operative review radiograph would show complete bone healing.

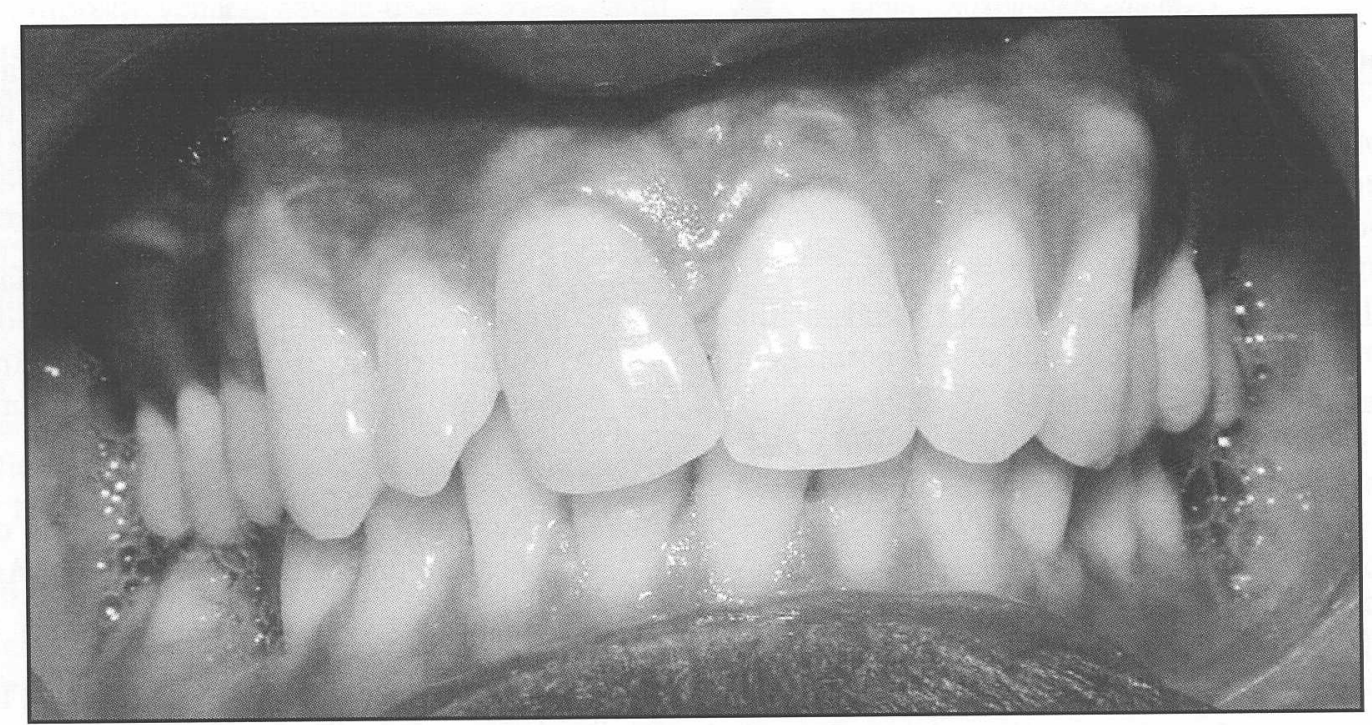

Figure 9: After 6-month post surgical.

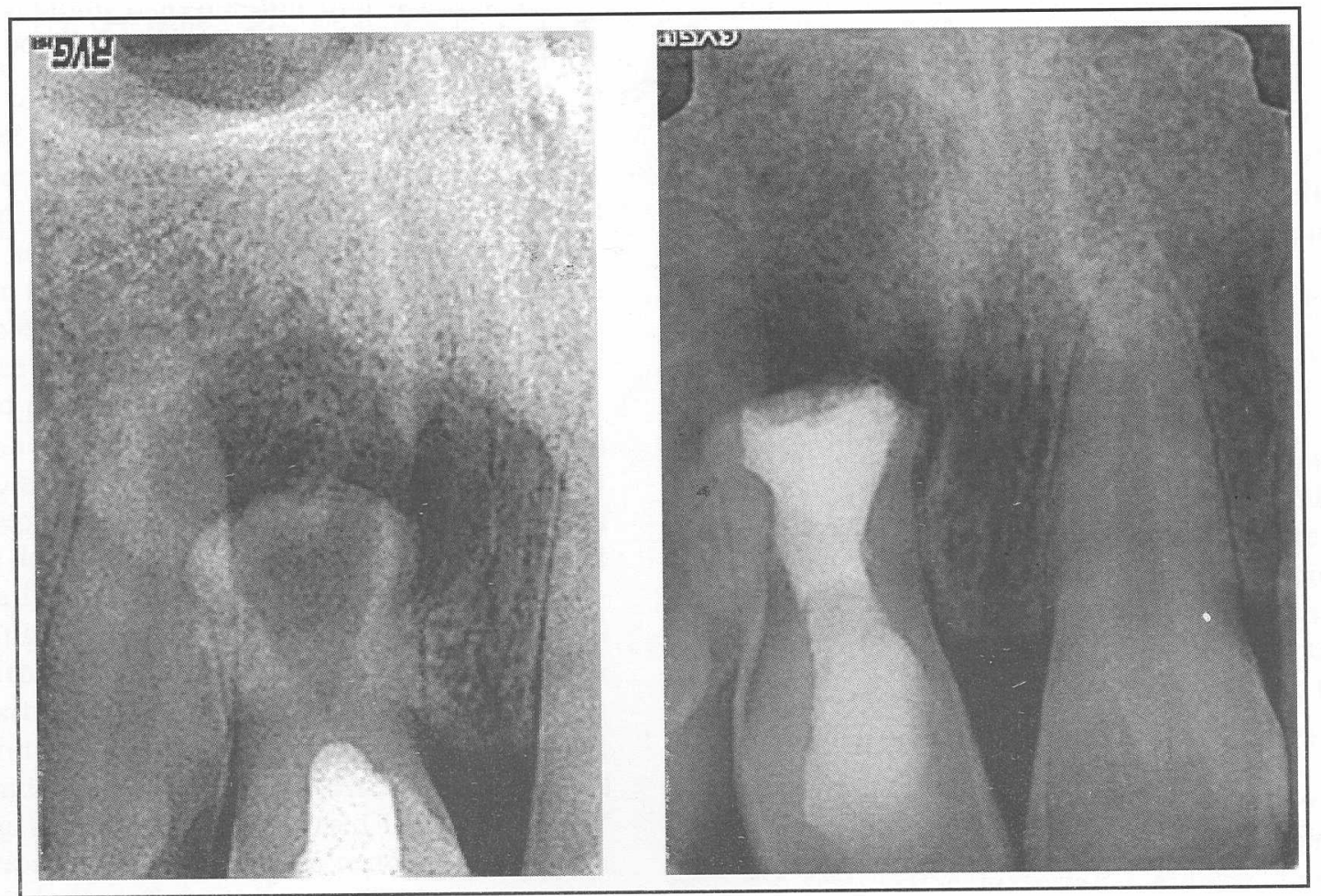

Figure 10: Periapical radiographs comparing preoperative and 6-month postoperative views. 


\section{REFERENCES}

1. Libfeld H, Stabholz A, Friedman S. Endodontic therapy of bilaterally geminated permanent maxillary central incisors. J Endodon 1986; 12: 214-6.

2. Greenfeld RS, Cambruui JV. Complexities of endodontic treatment of maxillary lateral incisors with anomalous root formation. Oral Surg Oral Med Oral Pathol 1986; 62: 82-8.

3. Hatton JF, Ferrillo PJ Jr. Successful treatment of a two-canaled maxillary lateral incisor. J Endodon 1989; 15: 216-8.

4. Peikoff MO, Trott JR. An endodontic failure caused by an unusual anatomical anomaly. $\mathbf{J}$ Endodon 1977; 3: 356-9.

5. Mueller AH. Anatomy of the root canals of the incisors, cuspids an bicuspids of the permanent teeth. J Am Dent Assoc 1933; 20: 1361-86.

6. Vertucci F. Root canal anatomy of the human teeth. Oral Surg 1984; 58: 588-99.

7. Lambruschini GM, Camps J. A two-rooted maxillary central incisor with a normal clinical crown. J Endodon 1993; 19: 95-6.

8. Michanowicz AE, Michanowicz JP, Ardila J, Posada A. Apical surgery on a two-rooted maxillary central incisor. J Endodon 1990; 16: 454-5.
9. Sinai I, Luspbader S. A dual maxillary central incisor. J Endodon 1984; 10:105-6.

10. Maguire A, Welbury RR. Long-term effects of antineoplastic chemotherapy and radiotherapy on dental development. Dental Update 1996; 23: 188-194.

11. Andreasen JO, Sundstrom B, Ravn JJ. The effect of traumatic injuries to primary teeth on their permanent successors, I. A clinical and histologic study of injured permanent teeth.Scandinavian Journal of Dental Research 1971; 79: 219-283.

12. Hall SR, Iranpour B. The effect of trauma on normal tooth development. Report of two cases. Journal of Dentistry for Children 1968; 35: 291295.

13. Andreasen JO, Munksgaard EC, Bakland LK. Comparison of fracture resistance in root canals of immature sheep teeth after filling with calcium hydroxide or MTA. Dent Trauma 2006; 22: $154-6$.

14. Kratchman SI. Perforation repair and one-step apexification procedures. Dent Clin N Am 2004; 48: 291-307.

15. Thomas von Arx. Failed Root Canals: The case for Apicoectomy (Periradicular Surgery). J Oral Maxillofac Surg 2005; 63: 832-37.

16. Hepworth MJ, Friedman S: Treatment outcome of surgical and non-surgical management of endodontic failures. J Can Dent Assoc 63: 364, 1997. 